\title{
Avaliação da sensibilidade de plantas jovens de quiabo (Abelmoschus esculentus (L.) Moench. - Malvaceae) ao ozônio
}

Patricia Bulbovas ${ }^{1}$, Silvia Maria Romano Sant'Anna ${ }^{2}$, Regina Maria de Moraes ${ }^{1}$, Elisabeth de Souza Lima ${ }^{2}$, Juliana Moreno Pina ${ }^{2}$, Marisia Pannia Esposito ${ }^{2}$, Maurício Lamano Ferreira ${ }^{2}$, Adriano Afonso Spielmann ${ }^{2}$, Ciliane Matilde Sollito ${ }^{2}$, Cynthia Hering Rinnert ${ }^{2}$, Denílson Fernandes Peralta ${ }^{2}$, Juliana da Silva Cardoso ${ }^{2}$, Lílian Carminitti ${ }^{2}$, Luciana da Silva Canêz ${ }^{2}$, Marcelo M. dos Santos Reis ${ }^{2}$, Michel Navarro Benatti ${ }^{2}$, Silvia Ribeiro de Souza ${ }^{1}$ e Marisa Domingos ${ }^{1,3}$

Recebido: 18.11.2007; aceito: 26.06.2008

ABSTRACT - (Assessment of the sensitivity of okra (Abelmoschus esculentus (L.) Moench. - Malvaceae) to ozone). The sensitivity of Abelmoschus esculentus to ozone $\left(\mathrm{O}_{3}\right)$ was assessed in plants exposed during four days, six hours/day, to filtered air (AF) and to $\mathrm{AF}$ plus $80 \mathrm{ppb}$ of $\mathrm{O}_{3}\left(\mathrm{AF}+\mathrm{O}_{3}\right)$ into fumigation chambers, by determining visible leaf symptoms and changes on gas exchange and on antioxidants. Visible symptoms were daily evaluated. Gas exchange and antioxidants (ascorbic acid and superoxide dismutase) were analyzed at the end of the experiment. All plants from $\mathrm{AF}+\mathrm{O}_{3}$ treatment showed leaf injury, characterized by interveinal reddish punctuations on the adaxial surfaces. In average, $15 \%$ of leaf injury index and $62 \%$ of severity were estimated. Net photosynthesis, stomatal conductance, transpiration rate, ascorbic acid level and superoxide dismutase activity were significantly reduced in those plants, compared to measurements performed in plants exposed to $\mathrm{AF}$ only. The results suggest that Abelmoschus esculentus is sensitive to ozone, showing low levels of antixidative defenses and physiological distubances.

Key words: Abelmoschus esculentus, antioxidants, gas exchange, ozone, visible foliar symptoms

RESUMO - (Avaliação da sensibilidade de plantas jovens de quiabo (Abelmoschus esculentus (L.) Moench. - Malvaceae) ao ozônio). A sensibilidade de Abelmoschus esculentus ao ozônio $\left(\mathrm{O}_{3}\right)$ foi determinada em plantas expostas por quatro dias, seis horas/dia, ao ar filtrado (AF) e ao AF enriquecido com 80 ppb de $\mathrm{O}_{3}\left(\mathrm{AF}+\mathrm{O}_{3}\right)$, em câmaras de fumigação, analisando-se sintomas foliares visíveis e alterações nas trocas gasosas e em antioxidantes. Avaliaram-se os sintomas foliares diariamente e as trocas gasosas e antioxidantes (ácido ascórbico e superóxido dismutase) ao fim do experimento. Todas as plantas em $\mathrm{AF}+\mathrm{O}_{3}$ apresentaram sintomas foliares, caracterizados por pontuações avermelhadas na superfície adaxial, entre as nervuras. Em média, o índice de injúria foliar foi de $15 \%$ e a severidade de $62 \%$. Fotossíntese líquida, condutância estomática, transpiração, concentração de ácido ascórbico e atividade da superóxido dismutase foram reduzidas significativamente nestas plantas, em comparação com as mantidas sob ar filtrado. Os resultados sugerem que Abelmoschus esculentus é sensível ao $\mathrm{O}_{3}$, apresentando baixos níveis de defesas antioxidativas e distúrbios fisiológicos.

Palavras-chave: Abelmoschus esculentus, antioxidantes, ozônio, sintomas foliares visíveis, trocas gasosas

\section{Introdução}

O ozônio $\left(\mathrm{O}_{3}\right)$ é formado na atmosfera por uma série de reações fotoquímicas, que ocorrem a partir de outros gases poluentes, como óxidos de nitrogênio $\left(\mathrm{NO}_{\mathrm{x}}\right)$ e hidrocarbonetos (Brasseur et al. 1999). Devido ao aumento das emissões desses precursores para a troposfera por ação antrópica, inclusive em países emergentes como China, Índia e Brasil, as concentrações de $\mathrm{O}_{3}$ têm aumentado substancialmente nas últimas décadas, tanto em regiões urbanas quanto em áreas rurais (Emberson et al. 2001, Krupa et al. 2001, Ashmore 2005). As previsões para o futuro, em escala mundial, são preocupantes, inclusive para o Brasil (Emberson et al. 2001, Ashmore 2005, CETESB 2007). Vingarzan (2004), por exemplo, baseado em modelos preditivos para os diferentes cenários climáticos futuros propostos pelo Painel Intergovernamental de Mudanças Climáticas (IPCC), afirma que as concentrações anuais globais de $\mathrm{O}_{3}$ poderá alcançar o valor de 70 ppb em 2050, devido especialmente ao aumento das emissões de $\mathrm{NO}_{x}$ e

1. Seção de Ecologia, Instituto de Botânica, Caixa Postal 3005, 01061-970, São Paulo, SP

2. Pós Graduação em Biodiversidade e Meio Ambiente, Instituto de Botânica, Caixa Postal 3005, 01061-970 São Paulo, SP

3. Autor para correspondência: mmingos@ superig.com.br 
ao transporte intercontinental, que excede os limites aceitos internacionalmente para a proteção da saúde humana e do meio ambiente.

$\mathrm{O} \mathrm{O}_{3}$ entra nas folhas por meio dos estômatos e, no espaço intercelular, reage com a água formando espécies ativas de oxigênio (EAO), que têm um alto potencial oxidativo (Samuelson \& Kelly 2001, Fuhrer \& Booker 2003, Baier et al. 2005). Entre estas espécies, encontram-se o radical superóxido $\left(\mathrm{O}_{2}{ }^{-}\right)$, o peróxido de hidrogênio $\left(\mathrm{H}_{2} \mathrm{O}_{2}\right)$, o radical hidroxila $\left(\mathrm{OH}^{\circ}\right)$ (Scandalios 1993) e o radical peridroxila $\left(\mathrm{O}_{2} \mathrm{H}^{\circ}\right)$ (Bray et al. 2000). Devido a essa natureza fortemente oxidativa, o $\mathrm{O}_{3}$ é um dos mais fitotóxicos entre os poluentes (Sanz et al. 2002, Iriti \& Faoro 2008).

Por serem altamente reativas, as EAO atacam moléculas vitais, como lipídios, proteínas e ácidos nucléicos, descaracterizando-as e causando distúrbios na célula vegetal (Foyer \& Noctor 2005). Como consequiências, são observados desequilíbrios bioquímicos, tais como efeitos sobre enzimas e sistemas enzimáticos e danos à membrana celular e de organelas, levando ao rompimento de diferentes cadeias metabólicas da célula e até a morte celular. Devido a esses efeitos na célula, aparecem lesões visíveis nos tecidos foliares como cloroses e necroses (Bray et al. 2000, Sanz et al. 2002).

Perturbações fisiológicas estão entre os efeitos mais freqüentemente observados em plantas expostas ao $\mathrm{O}_{3}$. Verificam-se especialmente alterações em várias etapas do processo fotossíntético, como reduções nas taxas de assimilação líquida de carbono, na condutância estomática e na fluorescência da clorofila a, com reflexos sobre o crescimento e alocação de biomassa (Morgan et al. 2003, Ashmore 2005, Filella et al. 2005). Por exemplo, Zheng et al. (2002), utilizando exemplares de Plantago major L., verificaram que a queda nas taxas fotossintéticas se deveu à redução na quantidade da enzima Rubisco, causada pelos distúrbios bioquímicos provocados pelo $\mathrm{O}_{3}$. Castagna et al. (2001), em testes com Cucurbita pepo L., mostraram que a redução na quantidade de $\beta$-caroteno causada pelo $\mathrm{O}_{3}$ desestabilizou o fotossistema II (PSII). Ainda, Novak et al. (2005) apontaram uma estreita relação entre injúrias foliares e queda na fotossíntese em três espécies lenhosas.

Contra a ação das EAO, com conseqüente minimização dos distúrbios bioquímicos e fisiológicos causados por elas, as células possuem defesas antioxidativas. Estas defesas podem inibir ou atrasar uma seqüência oxidativa, prevenir a formação de radicais, interceptar radicais e eliminar moléculas oxidadas (Bray et al. 2000, Baier et al. 2005). A ação antioxidativa ocorre através de um conjunto de substâncias enzimáticas ou não enzimáticas, que agem de forma integrada, e que estão presentes em organelas distintas da célula (Pereira et al. 2002, Long \& Naidu 2003, Gratão et al. 2005). Entre as enzimas, encontrase a superóxido dismutase (SOD), que catalisa a dismutação do radical superóxido, produzindo peróxido de hidrogênio (Becana et al.2000). Entre as substâncias não enzimáticas e solúveis em água está o ácido ascórbico, um agente redutor, que remove o radical superóxido, o radical hidroxila e o oxigênio singleto, sendo este último reduzido a radicais tióis. $\mathrm{O}$ ácido ascórbico também inibe reações desencadeadas pela ação das EAO e protege os lipídios da membrana (Conklin 2001). Portanto, os citados distúrbios em células e em tecidos vegetais ocorrerão a partir do momento em que o equilíbrio oxidante/antioxidante for rompido, sendo a eficiência com que tal sistema de defesas reduz a toxicidade das EAO, uma medida de tolerância das plantas ao $\mathrm{O}_{3}$.

Levantou-se a hipótese de que Abelmoschus esculentus (quiabo) é sensível ao $\mathrm{O}_{3}$, uma vez que foram observados sintomas foliares visíveis em plantas que cresciam em local da cidade de São Paulo afetado por altos níveis de contaminação por esse poluente, que se assemelhavam aos induzidos por $\mathrm{O}_{3}$ em outras espécies. Assim, este trabalho teve como objetivo avaliar o nível de sensibilidade de plantas jovens dessa espécie, quando submetidas a este poluente em condições controladas de fumigação, por meio da análise das mudanças na concentração ou atividade de antioxidantes, por um lado, e da ocorrência de distúrbios na fotossíntese e de danos foliares visíveis, por outro. O experimento teve por objetivo complementar a consolidação da formação de alunos matriculados na disciplina "Biomonitoramento da qualidade do ar com plantas", oferecida no âmbito do curso de pós-graduação sobre Biodiversidade e Meio Ambiente do Instituto de Botânica.

\section{Material e métodos}

Sementes de Abelmoschus esculentus, quiabo, foram germinadas em caixas gerbox e depois transferidas para sacos plásticos contendo substrato comercial Plantimax (Eucatex) e vermiculita fina, misturados na proporção de 3:1, respectivamente, o mesmo em que as sementes foram germinadas. Os sacos permaneceram em casa de vegetação com ar filtrado, no Instituto de Botânica, São Paulo, até o 
início do experimento, sobre caixas plásticas cobertas com tela de arame galvanizado. A irrigação adequada foi garantida por capilaridade através de cordões de náilon inseridos na base dos sacos, sendo que uma de suas extremidades permaneceu em contato com as raízes e a outra mergulhada em água de torneira contida na caixa (Arndt \& Schweizer 1991). As plantas de quiabo receberam solução nutritiva citada em Epstein (1975) para crescimento favorável (100 $\mathrm{mL}$ semanalmente) e estavam prontas para exposição quando apresentaram seis folhas, em média, cinco semanas após a semeadura.

A exposição de plantas de quiabo ao $\mathrm{O}_{3}$ ocorreu no período de 16 a 20 de abril de 2006, utilizando sistemas de câmaras fechadas, mantidas sob iluminação natural e sem sombreamento, em um local do Instituto de Botânica, São Paulo, SP. Estas câmaras consistem de filmes de teflon fixados em armação de aço inoxidável com dimensões de $85 \times 94 \times 85 \mathrm{~cm}$. Em sua parte inferior, há um suporte para vasos e, abaixo deste, um reservatório com água, ambos de aço inoxidável. Nessas câmaras, plantas de quiabo foram expostas a dois tratamentos: ar filtrado isento de poluentes (AF) e ar filtrado enriquecido com $80 \mathrm{ppb}$ de $\mathrm{O}_{3}\left(\mathrm{AF}+\mathrm{O}_{3}\right)$, por 6 horas diárias. Foram utilizadas quatro plantas em cada tratamento.

$\mathrm{O}$ ar introduzido nas câmaras foi captado do ambiente por um compressor e conduzido para um sistema de filtragem contendo filtro de sílica para desumidificação do ar e filtros de carvão ativado e de óxido de alumínio impregnado com permanganato de potássio, para eliminar contaminantes atmosféricos. Depois de filtrado, uma parte deste ar foi levada para uma das câmaras (AF) e outra para um compartimento que continha dois tubos cilíndricos, denominados misturadores. Nestes tubos ocorria a mistura do ar filtrado com o $\mathrm{O}_{3}$ gerado por um ozonizador, que foi, então, levado para a outra câmara $\left(\mathrm{AF}+\mathrm{O}_{3}\right)$. Por intermédio de válvulas, foi possível ajustar o fluxo de ar a $10 \mathrm{~L} /$ minuto para o interior de ambas as câmaras. $\mathrm{O}$ ar foi distribuído internamente por tubo de aço inox, contendo 25 orifícios (20 mm cada), instalado no centro das câmaras e em suas laterais, circundando todas as paredes. A saída do ar ocorreu pela parte superior das câmaras por meio de um tubo de aço inox com orifício de $47 \mathrm{~mm}$ de diâmetro. As concentrações horárias de $\mathrm{O}_{3}$ nessa última câmara, durante o experimento, foram medidas por meio de um analisador de $\mathrm{O}_{3}$ modelo EC $9810 \mathrm{~B}$ da marca Ecotech. Esses valores horários foram utilizados para estimar as doses acumuladas de $\mathrm{O}_{3}$ acima de $40 \mathrm{ppb}$
(AOT40), às quais as plantas do tratamento $\mathrm{AF}+\mathrm{O}_{3}$ estiveram submetidas.

Após o período de fumigação, realizaram-se, em sequiência, análises da área foliar afetada por sintomas visíveis atribuíveis ao $\mathrm{O}_{3}$, segundo Sanz et al. (2002), de parâmetros relacionados à fotossíntese e, finalmente, das concentrações de ácido ascórbico e da atividade da superóxido dismutase, tomados como indicadores da eficiência do sistema de defesas antioxidativas.

A avaliação de sintomas foliares, quando ocorreram, foi realizada por estimativa visual, sendo os resultados expressos inicialmente em porcentagem de área foliar afetada pelos sintomas, estimada em intervalos de 5\% (Novak et al. 2003). Em seguida, para melhor caracterização da intensidade de injúrias foliares ocorridas nas plantas mantidas no tratamento $\mathrm{AF}+\mathrm{O}_{3}$, contou-se o número de folhas com sintomas visíveis, agrupando-as, de acordo com a porcentagem de área afetada pelos mesmos, nas classes, de $5 \%\left(\mathrm{~N}_{1}\right)$, $>5 \%$ a $25 \%\left(\mathrm{~N}_{2}\right),>25 \%$ a $50 \%\left(\mathrm{~N}_{3}\right),>50 \%$ a $75 \%\left(\mathrm{~N}_{4}\right)$ e $>75 \%$ a $100 \%\left(\mathrm{~N}_{5}\right)$. Além disso, contou-se o número de folhas sem sintomas $\left(\mathrm{N}_{0}\right)$ por planta. $\mathrm{O}$ número de folhas em cada classe $\left(\mathrm{N}_{0}\right.$ a $\left.\mathrm{N}_{5}\right)$ foi usado para o cálculo do índice de injúria foliar (IIF) por planta usando-se a fórmula adaptada por El-Khatib (2003):

$\operatorname{IIF}(\%)=\frac{\left(\mathrm{N}_{1} \times 1\right)\left(\mathrm{N}_{2} \times 2\right)\left(\mathrm{N}_{3} \times 3\right)\left(\mathrm{N}_{4} \times 4\right)\left(\mathrm{N}_{5} \times 5\right)}{\left(\mathrm{N}_{0}+\mathrm{N}_{1}+\mathrm{N}_{2}+\mathrm{N}_{3}+\mathrm{N}_{4}+\mathrm{N}_{5}\right) \times 5} \times 100$

Também foi feito o cálculo de severidade de sintomas visíveis por planta, dividindo-se o número de folhas com sintomas pelo número total de folhas da planta, o qual também foi expresso em porcentagem.

As trocas gasosas foram analisadas nas plantas de ambos os tratamentos, ao término do experimento, por meio de um sistema de análise de gás por infravermelho (LI-6400, LI-COR, NE, USA). A assimilação líquida de $\mathrm{CO}_{2}\left(\mathrm{~A}_{1}\right)$, condutância estomática $\left(\mathrm{g}_{\mathrm{s}}\right)$ e transpiração (E) foram determinadas entre 9:00 e 10:30 h, na terceira folha a partir do ápice, que apresentavam o limbo totalmente expandido, sob condições do ambiente natural (em média, 370 ppb de $\mathrm{CO}_{2}, 19^{\circ} \mathrm{C}$ de temperatura, $90 \%$ de umidade relativa e entre 1.300 e $1.500 \mu \mathrm{mol} \mathrm{m}{ }^{-2} \mathrm{~s}^{-1}$ de densidade de fluxo de fótons fotossinteticamente ativos). Foram calculados os valores da eficiência instantânea da transpiração (EIT) e da eficiência intrínseca de uso da água (EiUA), por meio das razões $\mathrm{A}_{\mathrm{l}} / \mathrm{E}$ e $\mathrm{A} / \mathrm{g}_{\mathrm{s}}$, respectivamente. 
No laboratório, foram determinadas a concentração de ácido ascórbico total (AA) e a atividade da enzima superóxido dismutase (SOD) nas folhas de cada planta previamente analisadas quanto às trocas gasosas.

Para avaliar a concentração de AA, folhas frescas $(0,5 \mathrm{~g})$ foram homogeneizadas com $12 \mathrm{~mL}$ de solução aquosa de etileno diamina ácido tetracético - sal de sódio $\left(\right.$ EDTA- $\left.\mathrm{Na}_{2}\right)(0,07 \%)$ e ácido oxálico $(0,5 \%)$. $\mathrm{O}$ extrato resultante foi centrifugado $(40.000 \mathrm{~g}, \mathrm{t}=$ 30 minutos, $\left.\mathrm{T}=2{ }^{\circ} \mathrm{C}\right)$. Leituras foram realizadas em espectrofotômetro $(\lambda=520 \mathrm{~nm})$, após o acréscimo 2,5 $\mathrm{mL}$ de solução 2,6 diclorofenol-indofenol sal de sódio dihidratado (DCPiP) $(0,02 \%)$ (primeira leitura) e 0,05 $\mathrm{mL}$ de ácido ascórbico $1 \%$ ao sobrenadante (segunda leitura). O conteúdo de ácido ascórbico foi estimado a partir da diferença entre o branco e o resultado da diferença dessas leituras (Keller \& Schwager 1977).

Para determinar a atividade da enzima SOD, folhas frescas $(0,35 \mathrm{~g})$ foram homogeneizadas com polivinilpolipirrolidona (PVPP) e solução contendo tampão fosfato (50 mM, pH 7,5), EDTA- $\mathrm{Na}_{2} 1 \mathrm{mM}$, $\mathrm{NaCl} 50 \mathrm{mM}$ e ácido ascórbico $1 \mathrm{mM}$ e centrifugadas $\left(22.000 \mathrm{~g}, \mathrm{t}=25\right.$ minutos, $\left.\mathrm{T}=2^{\circ} \mathrm{C}\right)$. Ao sobrenadante, foram adicionados $0,5 \mathrm{~mL}$ de EDTA- $\mathrm{Na}_{2} 0,54 \mathrm{mM}, 0,8$ $\mathrm{mL}$ de tampão fosfato de potássio $(0,1 \mathrm{M}, \mathrm{pH} 7,0), 0,5 \mathrm{~mL}$ de metionina $0,13 \mathrm{mM}, 0,5 \mathrm{~mL}$ de azul $p$-nitrotetrazolio (NBT) $0,44 \mathrm{mM}$ e $0,2 \mathrm{~mL}$ de riboflavina $1 \mathrm{mM}$, e a solução resultante foi exposta a luz fluorescente $(80 \mathrm{~W})$ por 20 minutos. Extratos preparados seguindo o mesmo procedimento foram mantidos no escuro. A absorbância da solução foi medida em espectrofotômetro $(\lambda=560$ $\mathrm{nm}$ ) em ambos os tipos de extrato (iluminado e não iluminado), e a diferença entre as duas absorbâncias foi considerada para a determinação da atividade da SOD, que consistiu na inibição da redução do NBT, pela dismutação enzimática do superóxido (Osswald et al. 1992).

Durante todo o experimento, as condições de temperatura, umidade relativa e irradiação global foram monitoradas. A temperatura e umidade relativa do ar foram, em média para os quatro dias de experimento, de $17{ }^{\circ} \mathrm{C}$ e $87 \%$, respectivamente, com valores máximos e mínimos de temperatura de $22{ }^{\circ} \mathrm{C}$ e $13{ }^{\circ} \mathrm{C}$ e de umidade relativa de $97 \%$ e $60 \%$. A radiação solar global média foi de $10 \mathrm{MJ} \mathrm{m}^{-2}$ no período do experimento, com valores máximos de 17 $\mathrm{MJ} \mathrm{m}^{-2}$ nos dias ensolarados e mínimos de $8 \mathrm{MJ} \mathrm{m}^{-2}$ nos dias nublados.

$\mathrm{O}$ experimento foi disposto em delineamento inteiramente casualizado com dois tratamentos (AF e $\mathrm{AF}+\mathrm{O}_{3}$ ) e quatro repetições por tratamento. Os dados de trocas gasosas e de antioxidantes foram submetidos à análise de variância (one way ANOVA), sendo todo e qualquer contraste entre médias avaliado pelo teste " t'” de Student, uma vez que apresentaram distribuição normal, em nível de 5\% de probabilidade. As análises foram realizadas usando o programa Sigma Stat (Jandel Corporation Copyright $^{\circledR}$ 1992-1994).

\section{Resultados}

As plantas de A. esculentus do tratamento $\mathrm{AF}+\mathrm{O}_{3}$ apresentaram sintomas visíveis no quarto dia de experimento, quando a AOT40 atingiu o valor de 481 $\mathrm{ppb} \mathrm{h}^{-1}$. A AOT40 corresponde à soma dos valores horários de concentração de $\mathrm{O}_{3}$ no ambiente acima de 40 ppb, após subtração deste valor limite, não refletindo, portanto, o quanto de $\mathrm{O}_{3}$ foi efetivamente absorvido via estômatos. Por se tratar de um índice proposto para proteção de espécies vegetais européias, este foi aqui considerado apenas como uma forma de estabelecer um limite de exposição a partir do qual se verificou resposta visível ao $\mathrm{O}_{3}$ na espécie alvo.

Os danos surgiram apenas na parte adaxial da folha e se caracterizaram como pequenas pontuações irregulares de cor avermelhada entre as nervuras da folha (figura 1), obedecendo, portanto, os critérios para identificação do dano como sendo induzido pelo $\mathrm{O}_{3}$ (Schaub et al. 2001). O índice de injúria foliar (IIF) médio foi de $15 \%$, com valores por planta entre $13 \%$ e $20 \%$. A severidade média foi de $62 \%$, com valores por planta entre $33 \%$ e $75 \%$.

Estas mesmas plantas apresentaram redução significativa nos parâmetros de trocas gasosas avaliados em relação ao controle (figura 2). Esta

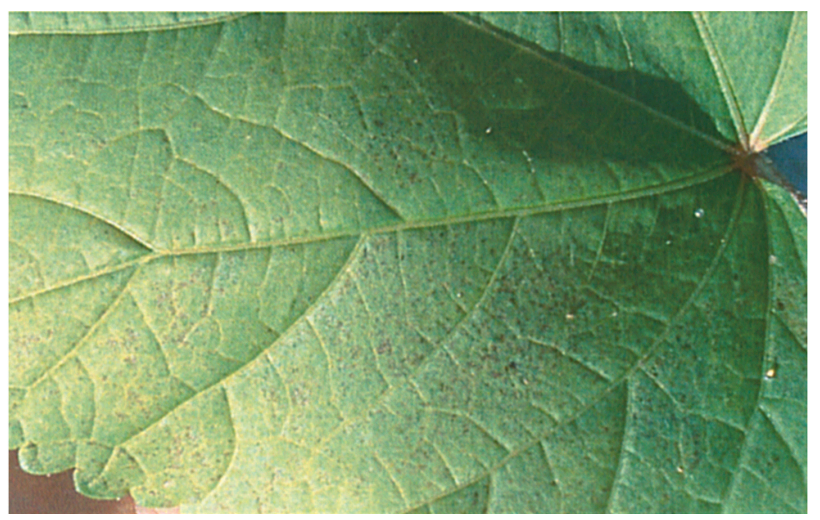

Figura 1. Sintomas visíveis (pontuações irregulares de cor avermelhada entre as nervuras) na superfície adaxial de folha de $A$. esculentus após exposição a 80 ppb de $\mathrm{O}_{3}$ por quatro dias (6 horas/ dia) em condições controladas de fumigação. 

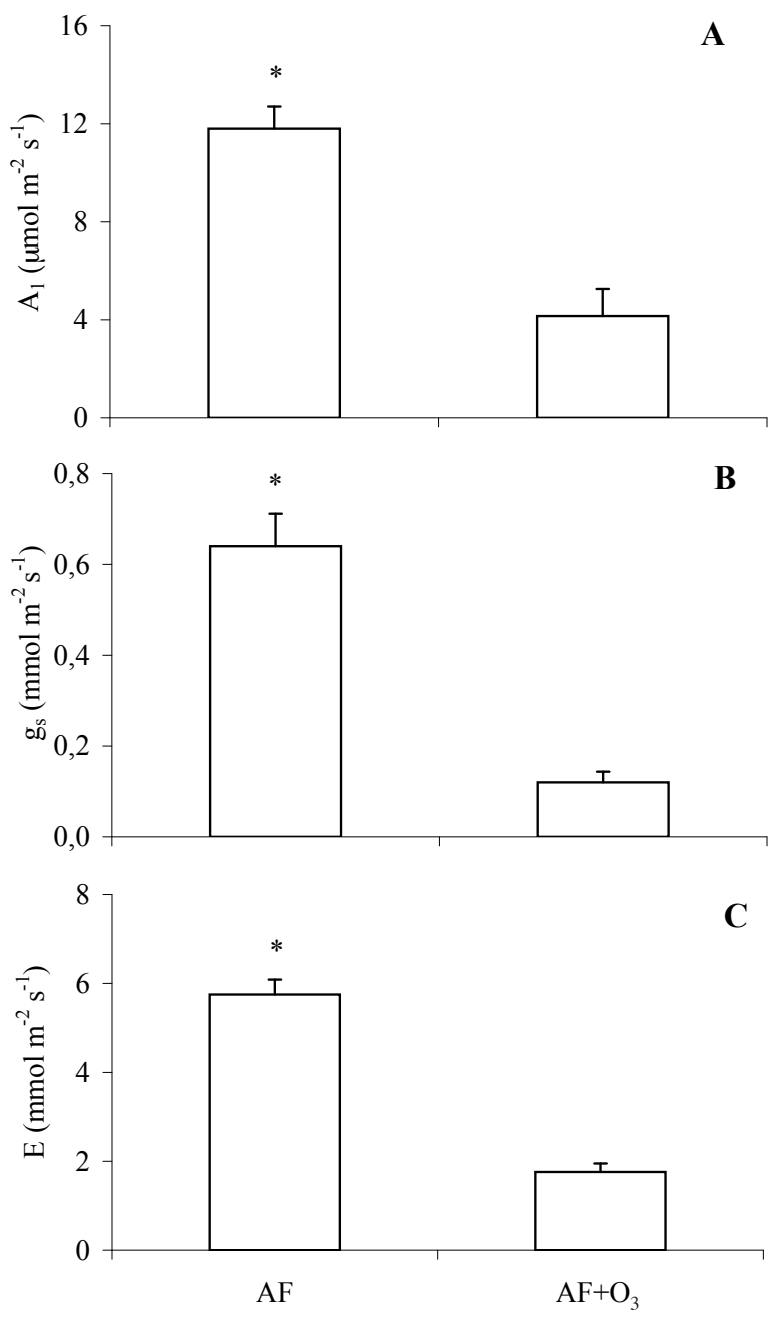

Figura 2. Taxas de assimilação líquida de $\mathrm{CO}_{2}-\mathrm{A}_{1}(\mathrm{~A})$, condutância estomática $-\mathrm{g}_{\mathrm{s}}(\mathrm{B})$ e transpiração $-\mathrm{E}(\mathrm{C})$ em plantas de A. esculentus expostas ao ar filtrado (AF) e a $80 \mathrm{ppb}$ de $\mathrm{O}_{3}$ por quatro dias - 6 horas/dia $\left(\mathrm{AF}+\mathrm{O}_{3}\right)$ em condições controladas de fumigação. * indicam diferenças significativas entre tratamentos, pelo teste " $t$ " em nível de 5\% de probabilidade. Valores representam a média \pm erro padrão.

redução foi de $65 \%$ para $\mathrm{A}_{1}, 81 \%$ para $\mathrm{g}_{\mathrm{s}}$ e $69 \%$ para E. Entretanto, não foram verificadas diferenças na EIT (em média, 2,5 \pm 0,4 para plantas expostas em $\mathrm{AF}+\mathrm{O}_{3}$ e 2,1 $\pm 0,5$ para plantas em $\mathrm{AF}$ ) e na EiUA (em média, 39,2 $\pm 1,6$ em $\mathrm{AF}+\mathrm{O}_{3}$ e 19,1 $\pm 0,7$ em AF). Estas últimas médias não foram significativamente diferentes devido à grande dispersão dos dados, que resultou em um desvio padrão alto em $\mathrm{AF}+\mathrm{O}_{3}$.

As defesas antioxidativas AA e SOD também foram significativamente mais baixas nas plantas do tratamento $\mathrm{AF}+\mathrm{O}_{3}$ (figura 3). A redução foi de $50 \%$ para AA e $40 \%$ para SOD.
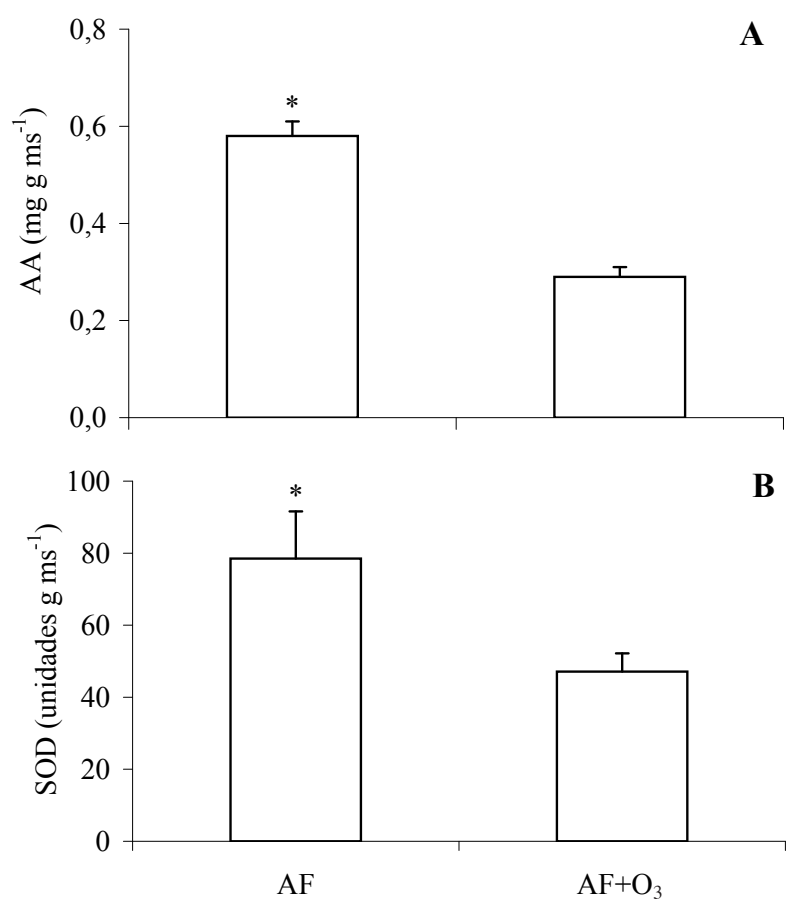

Figura 3. Valores médios da concentração de ácido ascórbico - AA (A) e atividade de superóxido dismutase - SOD (B), em plantas de A. esculentus expostas ao ar filtrado (AF) e a $80 \mathrm{ppb}$ de $\mathrm{O}_{3}$ por quatro dias - 6 horas/dia $\left(\mathrm{AF}+\mathrm{O}_{3}\right)$, em condições controladas de fumigação. * indicam diferenças significativas entre tratamentos, pelo teste " $t$ " em nível de $5 \%$ de probabilidade. Valores representam a média \pm erro padrão.

\section{Discussão}

Abelmoschus esculentus apresentou sensibilidade ao $\mathrm{O}_{3}$, mostrando sintomas foliares visíveis semelhantes aos encontrados em plantas que cresciam no local da cidade de São Paulo afetado por altos níveis de contaminação por esse poluente, confirmando a hipótese de trabalho levantada. Como observado no presente estudo, os danos atribuídos ao efeito deste poluente sobre plantas são, de uma forma geral, restritos a parte adaxial da folha, entre as nervuras, raramente ocorrendo na parte abaxial (Sanz et al. 2002). Além dos pontos de cor marrom a vermelho, determinados pelo acúmulo de pigmentos, os sintomas foliares podem ser pontuações amarelas ou porções de tecido foliar morto com diferentes tamanhos, formatos e cores, respectivamente denominadas cloroses e necroses. Por outro lado, manchas encontradas na parte abaxial são geralmente atribuídas a agressões mecânicas ou causadas por patógenos. 
Os sintomas visíveis observados nas folhas de A. esculentus podem ter sido em consequiência de distúrbios celulares, além dos fisiológicos medidos, que ocasionaram o acúmulo de antocianinas, o que pode explicar sua coloração avermelhada. Tais pontuações avermelhadas induzidas por $\mathrm{O}_{3}$ nas folhas, aliás, são comumente descritas na literatura para outras espécies. Furlan et al. (2007), por exemplo, encontraram esse mesmo tipo de sintoma foliar visível em plantas de Psidium guajava cv. Paluma em condições controladas de fumigação com $\mathrm{O}_{3}$.

Verificou-se, ainda, que os sintomas foliares visíveis em folhas de A. esculentus surgiram após curto período de exposição (quatro dias), sob concentrações de $\mathrm{O}_{3}$ realistas e geralmente observadas na cidade de São Paulo, como relata a CETESB (2007), e após exposição à baixa AOT40. Contudo, somente com base nessas informações, não se pode inferir sobre o nível de sensibilidade de plantas de A. esculentus ao $\mathrm{O}_{3}$. Primeiramente porque, em experimentos realizados sob condições experimentais, as respostas das plantas podem ser mais intensas do que daquelas mantidas em ambiente natural, quando expostas à mesma AOT40. Além disso, segundo Matyssek et al. (2004), esse índice não indica a dose acumulada do poluente no interior da folha, ou seja o quanto deste foi efetivamente absorvido via estômatos. Deve-se considerar, ainda, que múltiplos fatores ambientais de estresse nas condições de campo, ao afetarem a condutância estomática das plantas, podem alterar o fluxo do poluente para o interior da folha. Inclusive, por esses motivos, a eficiência da AOT40 para proteção de espécies vegetais européias, para o que foi proposto, tem sido bastante questionada por diversos autores, entre os quais Matyssek et al. (2004) e Uddling et al. (2004). Portanto, o nível de sensibilidade de plantas de A. esculentus ao $\mathrm{O}_{3}$ somente poderá ser determinado, em estudos combinados de laboratório e de campo, propondo-se curvas do tipo dose $\mathrm{x}$ resposta entre $\mathrm{o}$ fluxo de $\mathrm{O}_{3}$ para o interior das plantas e a intensidade de danos metabólicos, fisiológicos e ou visíveis.

Reduções nas respostas antioxidativas e nas taxas fotossintéticas, observadas no presente estudo, reforçam a suposição de que plantas de A. esculentus são sensíveis ao $\mathrm{O}_{3}$.

A capacidade antioxidativa das plantas mantidas em $\mathrm{AF}+\mathrm{O}_{3}$ para conter a ação tóxica dos sub-produtos oxidativos do $\mathrm{O}_{3}$ ou até para produzir ou regenerar os antioxidantes analisados (AA e SOD) pareceu limitada. Isto porque, mesmo considerando que as defesas antioxidativas foram alteradas nessas plantas, ocorreu redução na taxa fotossintética. Os resultados de EIT e EiUA, entretanto, não foram conclusivos, indicando a necessidade de novos estudos.

Moraes et al. (2002), estudando os efeitos de poluentes sobre algumas espécies frutíferas na região de Cubatão, observaram redução da concentração ácido ascórbico em plantas de Psidum guajava L. expostas em ambiente poluído, e também relacionaram esta redução a possíveis distúrbios na síntese desse antioxidante, ou ao alto consumo do mesmo devido ao aumento na formação de EAO provocadas por poluentes atmosféricos. O mesmo foi observado em plantas de Tibouchina pulchra (Cham.) Cogn. expostas nos mesmos locais em Cubatão (Moraes et al. 2003).

A intensidade diferenciada de respostas antioxidativas pode indicar graus distintos de suscetibilidade de espécies vegetais ao $\mathrm{O}_{3}$, mesmo pertencentes ao mesmo gênero. Por exemplo, Trifolium repens $\mathrm{L}$. apresentou maior quantidade de AA e maior atividade de SOD quando submetida ao poluente e não apresentou sintomas foliares, sendo caracterizada como tolerante. Trifolium pratense L., por sua vez, sob as mesmas condições de exposição, não teve um aumento nos seus níveis de antioxidantes, e mostrou injúrias foliares, tendo sido considerada sensível (Scebba et al. 2003).

A diminuição da $\mathrm{A}_{1}$ nas plantas expostas ao $\mathrm{O}_{3}$ pode ter sido causada por distúrbios em várias etapas do processo fotossintético. Esses distúrbios são conseqüências do estresse oxidativo ocasionado pela produção de EAO e dos baixos níveis de antioxidantes observados. Estas EAO reagem com substâncias envolvidas em etapas da carboxilação, como a síntese da ribulose bifosfato carboxilase-oxigenase (Rubisco), que é a enzima responsável pela assimilação de $\mathrm{CO}_{2}$ (Pell et al. 1994, Farage \& Long 1999, Zheng et al. 2002). A inibição de etapas da carboxilação também pode causar de decréscimo da $\mathrm{g}_{\mathrm{s}}$ como uma forma de manter a concentração de $\mathrm{CO}_{2}$ interna (Heath 1994). A redução da $A_{1}$ acompanhada por menor taxa de $g_{s}$, observada neste estudo, pode ser efeito não somente de problemas em etapas da carboxilação, como descrito acima, como também do fechamento estomático induzido pelo $\mathrm{O}_{3}$.

A $g_{s}$ é comumente reduzida na presença do $\mathrm{O}_{3}$. Entretanto, alguns estudos conduzidos sob determinadas condições ambientais têm questionado se as alterações nos valores de $\mathrm{g}_{\mathrm{s}}$ são causadas pelos efeitos do $\mathrm{O}_{3}$ sobre o complexo estomático ou sobre a $\mathrm{A}_{1}$ (Zheng et al. 2002). Já Castagna et al. (2001) 
consideram que, em folhas maduras, a queda em $\mathrm{g}_{\mathrm{s}}$ está relacionada à redução da eficiência da carboxilação, não sendo a causa primária da queda na $\mathrm{A}_{1}$.

Novak et al.(2005), trabalhando com três espécies arbóreas sensíveis ao $\mathrm{O}_{3}$, verificaram que as maiores reduções nas trocas gasosas ocorreram nas folhas que apresentavam sintomas foliares visíveis, como foi verificado no presente estudo, em que as folhas das plantas mantidas sob ar filtrado apresentaram-se íntegras e com taxas de $\mathrm{A}_{1}$ mais elevadas, enquanto as de $\mathrm{AF}+\mathrm{O}_{3}$ tinham danos e $\mathrm{A}_{1}$ reduzida.

Os dados obtidos no presente estudo, em seu conjunto, sugerem que A. esculentus é uma espécie sensível ao $\mathrm{O}_{3}$. A capacidade antioxidativa das plantas mantidas no tratamento $\mathrm{AF}+\mathrm{O}_{3}$ para conter a ação tóxica do $\mathrm{O}_{3}$ ou até para produzir ou regenerar os antioxidantes analisados pareceu limitada, uma vez que ocorreram distúrbios fisiológicos, como reduções em parâmetros relacionados à fotossíntese, e que surgiram pontuações avermelhadas visíveis sobre a superfície adaxial das folhas tipicamente induzidas por $\mathrm{O}_{3}$ em outras espécies vegetais. Entretanto, novos experimentos devem ser realizados para melhor estabelecer limites de respostas desta espécie ao poluente e, assim, determinar seu nível de sensibilidade ao mesmo.

\section{Agradecimentos}

Os autores agradecem à Fundação de Amparo à Pesquisa do Estado de São Paulo (FAPESP), por financiar a construção do sistema de fumigação (Processo 02/04751-6), ao Prof. Dr. Welington B.C. Delitti (Depto de Ecologia Geral, Instituto de Biociências, USP), pelo empréstimo do analisador de gases por infravermelho, à funcionária de Seção de Ecologia, do Instituto de Botânica, SP, Amariles Celsa de Souza, pelo cultivo das plantas de quiabo usadas no experimento e ao IAG pelos dados de radiação solar global fornecidos.

\section{Literatura citada}

Arndt, U. \& Schweizer, B. 1991. The use of bioindicators for environmental monitoring in tropical and subtropical countries. In: H. Ellenberg, U. Arndt, R. Bretthauer, B. Ruthsatz \& L. Steubing (eds.). Biological Monitoring. Signals from the Environment. Vieweg, Eschborn. pp. 199-298.

Ashmore, M.R. 2005. Assessing the future global impacts of ozone on vegetation. Plant, Cell and Environment 28: 949-964.
Baier, M., Kandlbider, A., Golldack, D. \& Dietz K.J. 2005. Oxidative stress and ozone: perception, signaling and response. Plant, Cell and Environment 28: 10121020.

Becana, M., Dalton, D.A., Moran, J.F., Iturbe-Ormaetxe, I., Matamoros M. \& Rubio, M.C. 2000. Reactive oxygen species and antioxidants in legume nodules. Physiologia Plantarum 109: 372-381.

Brasseur, G.P., Orlando, J.J. \& Tyndall, G.S. 1999. Atmospheric chemistry and global change. Oxford University Press, New York

Bray, E.A., Bailey-Serres, J. \& Weretilnyk, E. 2000. Responses to abiotic stresses. In: B.B. Buchanan, W. Gruissen \& R.L. Jones (eds.). Biochemistry \& Molecular Biology of Plants. American Society of Plant Physiologists, New York. pp. 1158-1203.

Castagna, A., Nali, C., Ciompi, S., Lorenzini, G., Soldatini, G.F. \& Ranieri, A. 2001. Ozone exposure affects photosynthesis of pumpkin (Cucurbita pepo) plants. New Phytologist 152: 223-229.

CETESB. 2007. Relatório de qualidade do ar no Estado de São Paulo 2006. Série Relatórios/ Secretaria do Estado do Meio Ambiente, São Paulo.

Conklin, P.L. 2001. Recent advances in the role and biosynthesis of ascorbic acid in plants. Plant, Cell and Environment 24: 383-394.

El-Khatib, A.A. 2003. The response of some common Egyptian plants to ozone and their use as biomonitors. Environmental Pollution 124: 419-428.

Emberson, L.D., Ashmore, M.R., Murray, F., Kuylenstierna, J.C.I., Percy, K.E., Izuta, T., Zheng, Y., Shimizu, H., Sheu, B.H., Liu, C.P., Agrawal, M., Wahid, A., Abdel-Latif, N.M., van Tienhoven, M., de Bauer, L.I. \& Domingos, M. 2001. Impacts of air pollution on vegetation in developing countries. Water, Air, and Soil Pollution 130: 107-118.

Epstein,E. 1975. Nutrição mineral das plantas. Princípios e perspectivas. 1 ed. Livros Técnicos e Científicos, Rio de Janeiro.

Farage, P.K. \& Long, S.P. 1999. The effects of ozone fumigation during leaf development on photosynthesis of wheat and pea: an in vivo analysis. Photosynthesis Research 59: 1-7.

Filella, I., Peñuelas, J. \& Ribas, A. 2005. Using plant biomonitors and flux modeling to develop $\mathrm{O}_{3}$ doseresponse relationships in Catalonia. Environmental Pollution 134: 145-154.

Foyer, C.H. \& Noctor, G. 2005. Oxidant and antioxidant signaling in plants: a re-evaluation of the concept of oxidative stress in a physiological context. Plant, Cell and Environment 28: 1056-1071.

Fuhrer, J. \& Booker, F. 2003. Ecological issues related to ozone: agricultural issues. Environmental International 29: 141-154. 
Furlan, C.M., Moraes, R.M., Bulbovas, P., Domingos, M., Salatino, A. \& Sanz, M.J. 2007. Psidium guajava 'Paluma' (the guava plant) as a new bio-indicator of ozone in the tropics. Environmental Pollution 147: 691-695.

Gratão, P.L., Prasad, M.N.V., Cardoso, P.F., Lea, P.J. \& Azevedo, R.A. 2005. Phytoremediation: green technology for the clean up of toxic metals in the environment. Brazilian Journal Plant Physiology 17: 53-64.

Heath, R.L. 1994. Possible mechanisms for the inhibition of photosynthesis by ozone. Photosynthesis Research 39: 439-451.

Iriti, M.\& Faoro, F. 2008. Oxidative stress, the paradigm of ozone toxicity in plants and animals. Water, Air and Soil Pollution 187: 295-301.

Jandel Corporation. 1992-1994. SigmaStat statistical software: user's manual. San Rafael, pp. 831.

Keller, T. \& Schwager, H. 1977. Air pollution and ascorbate. European Journal of Forest Pathology 7: 338-350.

Krupa, S., McGrath, M. \& Andersen, C. 2001 . Ambient ozone and plant health. Plant Disease 85: 4-12.

Long, S.P. \& Naidu, S.L. 2003. Effects of oxidants at the biochemical, cell and physiological levels, with particular reference to ozone. In: J.N.B. Bell \& M. Treshow (eds.). Air Pollution and Plant Life. John Wiley \& Sons, London. pp. 69-88.

Matyssek, R., Wieser, G., Nunn, A.J., Kozovits, A.R., Reiter, I.M., Heerdt, C., Winkler, J.B., Baumgarten, M., Häberle, K.H., Grams, T.E.E., Werner, H., Fabian, P. \& Havranek, W.M. 2004. Comparison between AOT40 and ozone uptake in forest trees of different species, age and site conditions. Atmospheric Environment 38: 2271-2281.

Moraes, R.M., Delitti, W.B.C. \& Moraes, J.A.P.V. 2003. Gas exchange, growth, and chemical parameters in a native Atlantic forest tree species in polluted areas of Cubatão, Brazil. Ecotoxicology and Environmetal Safety 54: 339-345.

Moraes, R.M., Klumpp, A., Furlan, C.M., Klumpp, G., Domingos, M., Rinaldi M.C.S. \& Modesto, I.F. 2002. Tropical fruit trees as bioindicators of industrial air pollution in southeast Brazil. Environmental international 28: 367-374.

Morgan, P.B., Ainsworth, E.A. \& Long S.P. 2003. How does elevated ozone impact soybean? A meta-analysis of photosynthesis, growth and yield. Plant, Cell and Environment 26: 1317-1328.

Novak, K., Skelly, J.M., Schaub, M., Kräuchi, N., Hug, C., Fuhrer, J., Landolt, W. \& Bleuler, P. 2003. Ozone air pollution and foliar injury development on native plants of Switzerland. Environmental Pollution 125: 41-52.

Novak, K., Schaub, M., Fuhrer, J., Skelly, J.M., Hug, C., Landolt, W., Bleuler,P. \& Kräuchi, N. 2005. Seasonal trends in reduced leaf gas exchange and ozone-induced foliar injury in three ozone sensitive woody plant species. Environmental Pollution 136: 33-45.

Osswald, W.F., Kraus, R., Hippeli, S., Benz, B., Volpert, R. \& Elstner, E.F. 1992. Comparison of the enzymatic actives of dehydroascorbic acid redutase, glutathione redutase, catalase, peroxidase and superoxide dismutase of healthy and damaged spruce needles (Picea abies (L.) Karst). Plant Physiology 139: 742-748.

Pell,E.J., Eckardt, N.A. \& Glick, R.E. 1994. Biochemical and molecular basis for impairment of photosynthetic potential. Photosynthesis Research 39: 453-462.

Pereira, G.J.G., Molina, S.M.G., Lea, P.J. \& Azevedo, R.A. 2002. Activity of antioxidant enzymes in response to cadmium in Crotalaria juncea. Plant and Soil 239: 123-132.

Samuelson, L. \& Kelly J.M. 2001 . Scaling ozone effects from seedlings to forest tress. New Phytologist 149: 21-41.

Sanz, M.J., Sánchez, G., Calatayud, V., Minaya, M.A. \& Cerveró, J. 2002. La contaminación atmosférica en los bosques: guía para la identificación de daños visibles por ozono. $1^{\mathrm{a}}$ ed. Artegraf, Madrid.

Scandalios, J.G. 1993. Oxygen stress and superoxide dismutases. Plant Physiology 101: 7-12.

Scebba, F., Pucciarelli, I., Soldatini, G.F. \& Ranieri, A. 2003. $\mathrm{O}_{3}$ induced changes in the antioxidant systems and their relationship to different degrees os susceptibility of two clover species. Plant Science 165: 583-593.

Schaub, M., Bassin, S. \& Kräuchi, N. 2001. Assessment of ozone visible injury on 16 ICP-forests level II Plots in Switzerland. www.ozone.wsl.ch/lwf\%20assess.pdf (acesso em 15.10.2007)

Uddling, J., Günthardt-Goerg, M. S., Matyssek, R., Oksanen, E., Pleijel, H., Selldén, G. \& Karlsson, P.E. 2004. Biomass reduction of juvenile birch is more strongly related to stomatal uptake of ozone than to indices based on external exposure. Atmospheric Environment 38: 4709-4719.

Vingarzan, R. 2004. A review of surface ozone background levels and trends. Atmospheric Environment 38: 34313442 .

Zheng, Y., Shimizu, H.\& Barnes, D. 2002. Limitations to $\mathrm{CO}_{2}$ assimilation in ozone-exposed leaves of Plantago major. New Phytologist 155: 67-78. 